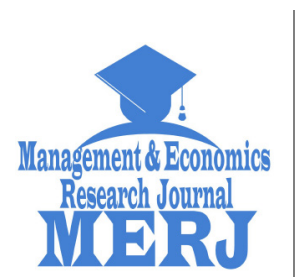

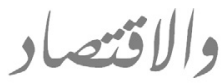

Management \& Economics Research Journal

ISSN 2710-8856 (Online)

ISSN 2676-184X (Print)

Vol. 4 No. 1 (2022): March, pp. 54-80

https://doi.org/10.48100/merj.2022.174

Check for updates

\title{
Performance Management Practices and Motivation in Developing Countries: A Further Validation of the Public Service Motivation Construct in Ghana
}

\author{
Juliana Abagsonema Abane ${ }^{1} \mathbb{D}$, Boon-Anan Phinaitrup ${ }^{2}$ \\ ${ }^{1} \mathrm{PhD}$ degree, Lecturer, Department of History and Political Studies, Kwame Nkrumah \\ University of Science and Technology (Ghana) \\ $\triangle$ abanejulie@gmail.com \\ ${ }^{2} \mathrm{PhD}$ degree, Associate Professor, Graduate School of Public Administration (GSPA), \\ NIDA (Thailand) \\ $\triangle$ boon@nida.ac.th
}

Received: 15-12-2021

Accepted: 24-01-2022

Published online: 26-01-2022

How to Cite:

Abane, J. A., \& Phinaitrup, B. (2022). Performance Management Practices and Motivation in Developing Countries: A Further Validation of the Public Service Motivation Construct in Ghana. Management \& Economics Research Journal, 4(1), 54-80. https://doi.org/10.48100/merj.122.174

\begin{abstract}
:
This study aims to test if the local government's performance management practices are predicted by their employee's public service motivation levels. Local government's performance management practices are effective when their employees are committed and motivated. Employees whose motivations are unique to public institutions will be committed to both their key performance indicators and the general strategic goals of the local government's core mission. The lack of such motivations may be detrimental to the practice of management at the local level. The study used a crosssectional survey of 850 local government employees in the Greater Accra of Ghana. The method of analysis of the data was multiple regression
\end{abstract}

•Corresponding author: Department of History and Political Studies, KNUST (Ghana).

[ $₫$ abanejulie@gmail.com]

(C2022 the Author(s). This is an open-access article distributed under the terms of (CC BY-NC 4.0) which permits use, distribution and reproduction in any medium, provided the original work is properly cited and is not used for commercial purposes. 
techniques. The findings suggest that employees' scores on attraction to policymaking, civic duty, and commitment to the public interest are strongly positively associated with performance management practices. The regression analysis demonstrated that public service motivation subscales combined to predict the variance in the dependent variable. Several performance management studies examine federal government utilization and rational decision-making processes. However, this study is one of the few to examine performance management practices of local governments and public service motivation theory by showing that employees' public service motivation levels can significantly predict the changes in performance management practices.

Keywords: Developing Countries, Ghana, Motivation, Performance Management Practices, Public Service Motivation Construct.

JEL Codes: M1, M12, M19.

\section{Introduction}

Performance management (PM) is vital for organizations and their employees to achieve their goals, increase value to citizens, and deliver quality public services. Although PM has been an old organizational performance tool in the private sector, recent developments suggest a widespread adoption by local governments in the public management literature (Abane \& Phinaitrup, 2017; Ammons \& Roenigk, 2015). Similarly, research on PM over the years has concentrated on the measurement system (Ammons \& Rivenbark, 2008; Hoontis \& Kim, 2012), metric difficulty (Cavalluzzo \& Ittner, 2004), goal clarity (Hoontis \& Kim, 2012; Moynihan et al., 2012), and political support (Moynihan et al., 2012; Yang \& Hsieh, 2007). While these studies are essential for the effective implementation of PM policies, little information is available to explain how employees' motivations can help implement PM.

Motivation has been one of the subjects of contention in public sector discourse, and the disagreement bothers on whether or not all types of motivations are suitable for reinforcing desirable behaviour in public organizations. The public management literature notes that not all types of motivations can increase performance among public employees (Houston, 2000; Perry \& Wise, 1990; Perry \& Hondeghem, 2008). Scholarly literature demonstrates that some motivational types are better at achieving results than others, and one such motivational tool used in the public sector is public service motivation (PSM) (Andersen et al., 2014; Homberg \& McCarthy, 2015; Perry, 1996). 
Further, the evidence suggests that PM can motivate employees to perform their best. This is so with the current ideas on performance-based funding or performance-based grant in the public sector. To the extent that PM can motivate employees, it is important to understand how this link can be tested using one of the employee motivational types specific to public sector organizations. According to Pandey (2015, p.1), PM research "promises to be a long one," and the topic has surged in the last two decades, which will continue to increase in the next decade. This is because evidence of its effectiveness is mixed, and many developing countries are beginning to use the elements of PM in the management of public policies and programs at the local level (Abane \& Phinaitrup, 2017; Mmieh et al., 2011; Ohemeng, 2011; Public Services Commission, 2012).

Despite the extensive research on the subject, there is inconclusive evidence on whether or not motivation can influence its effectiveness in LGs. For example, few studies have explored the relationship between PSM and PM (Christensen et al., 2013; Lynggaard et al., 2018). These studies have contributed to our understanding of the significance of PSM and its link with the PM system. However, the findings provide little understanding of how PSM contributes to local government authorities' PM best practices, especially regarding their strategic planning, performance monitoring \& evaluation, review, and improvement. These four best practices are considered the complete phase of an effective PM cycle in organizations (Armstrong \& Baron, 2007). This study examines how individual PSM levels (measured by five subscales: attraction to policymaking, commitment to the public interest, civic duty, compassion, and self-sacrifice) influence the effectiveness of LGs PM best practices. The results showed that employees' PSM scores significantly correlate with LGs PM best practices. However, the subscales have different effect sizes.

This study adds to the current body of research on PM and PSM (Christensen et al., 2013; Kroll \& Vogel, 2013; Moynihan \& Pandey, 2010). Though there is significant research on PM in LGs (Ammons \& Roenigk, 2015; Baird, Kevin \& Schoch, Herbert \& Chen, 2012; Boyne, 2002; Moynihan \& Pandey, 2010; Nurkholis et al., 2014), this has generally been studied at the executive agencies and the councils' levels. Consequently, few studies directly study local government (LG) employees' PSM levels and their impact on PM, especially in sub-Saharan Africa. Therefore, the study aims to test the effect of the 1996 PSM construct (Perry, 1996) on PM best practices of LGs in Ghana and to explain how PSM contributes to the effectiveness of LG PM policies. Testing Perry's (1996) PSM construct on LGs PM best practices from a developing country's perspective will help to shape the PSM 
theory and add knowledge from the Ghanaian experience. This since South Africa is the only known country that was part of the 150 samples used to test the PSM's 1996 construct (Perry \& Hondeghem, 2008).

\section{Literature review}

\subsection{Performance management practices (PMPs)}

PM is a multidimensional concept that focuses on how organizations combine operational bundles to achieve their key performance indicators (KPIs) by following steps to implement their goals and measure their performance (Biron et al., 2011; Lee, 2005). Some scholars see PM as a strategic and tactical process that helps improve employees' performance (Abane \& Phinaitrup, 2017; Biron et al., 2011). Others view PM as a systematic approach to people management where organizational and individual activities are geared toward goal attainment (Maley, 2014; Waal \& Counet, 2009). Subsequently, PMPs may be viewed as a systematically structured bundle of activities for setting goals, measuring, evaluating, reviewing, and influencing employees' performance. At the same time, it is a tactical tool that top management uses to achieve their goals (Biron et al., 2011).

In the literature, PMPs have four important bundles: strategic planning, performance monitoring \& evaluation, performance review, and performance improvement (Ammons \& Roenigk, 2015). Strategic planning involves a formal setting of objectives and goals which cascade the organizational goals to individual goals (Dewettinck \& van Dijk, 2013). Performance monitoring and evaluation is a careful plan of action to supervise and assess employees' KPIs for effective implementation (Amirkhanyan et al., 2014), while performance review assesses the achievement or otherwise of the individual KPIs. While performance reviews can take the form of a quarterly, mid-year, annual review, or a combination of any of these in a given year. (Biron et al., 2011; Dahling \& O'Malley, 2011; Favero et al., 2016; Gill $\&$ Carter, 2016; Nielsen, 2014).

Performance improvement constitutes the developmental approach to managing performance (Abane \& Phinaitrup, 2017; Maley, 2014; Sanderson, 2001). It can be viewed as a corrective measure of employee performance by modifying their skill set to enhance future performance through training and capacity building. The primary function of performance improvement is to ensure that employees enhance their previous scores on their KPIs and acquire skills and knowledge that may be relevant to their job descriptions. Further, at this stage, employees can be incentivized through different 
motivational strategies with the view that such incentives will push them to improve their performance. Unfortunately, this component of PMBP has not received attention in public organizations (Andersen et al., 2014; Halachmi, 2002; Hawke, 2012; Koike, 2013; Sanderson, 2001). Therefore, this paper aims to investigate the relationship between PSM and its effect on PMPs, and LGs can use their employees' PSM to support performance at the local level.

\subsection{Public service motivation (PSM)}

PSM has been variously linked to prosocial behaviour in organizations (Brief and Motowidlo, 1986; Campbell et al., 2016; Francois, 2000; Grant, 2008a; Moynihan et al., 2012), altruistic (Campbell et al., 2016; Piliavin \& Charng, 1990). In contrast, Perry \& Hondeghem (2008) maintain that prosocial behaviour is mostly viewed as voluntary action towards others without expecting a return (Brief \& Motowidlo, 1986), while altruism refers to deliberate individual action directed toward individuals or groups to promote their welfare (Kim, 2006). However, Perry and Hondeghem (2008) view altruism and PSM as complementary constructs. Subsequently, they refer to it as a specific expression of prosocial, other-oriented motives, goals, and values (Perry \& Hondeghem, 2008; Vandenabeele, 2007).

According to Vandenabeele (2007: 549), PSM refers to beliefs and values that transcend the self and organizational interests favouring social and political domains. Similarly, Brewer and Selden (1998: 417) view PSM as a motivational force that induces meaningful performance from employees in public organizations. The common denominator in the PSM definition is that it is a type of motivation vested in public institutions. This compelling force can elicit an excellent and meaningful performance from public employees. This study defines PSM as a motivational tool in public organizations to benefit from the organization's internal and external environment, whether in a public or private setting. Following Perry \& Wise (1990) and (Perry, 1996), this study conceives PSM to be measured by three motives: rational, normbased, and affective motives (Perry, 1996).

The literature on PSM is vast. The subject continues to receive much attention, which will continue for a while. The reason behind the continuous focus on the idea is that motivated employees will increase their task performance. Although PSM research has increased over the past 20 years (Christensen et al., 2017; Ritz et al., 2016), there have been uncertainties and ambiguities in understanding the concept with other concepts like altruism and the publicness of the construct (Bozeman \& Su, 2015; Bullock et al., 2015). 
Consequently, Perry and Hondeghem (2008) and Christensen et al. (2017) trace two research tracks. The first track incorporates other-regarding orientations from disciplines outside public management. It focuses on employee motivation in organizations (Christensen et al., 2013; GouldWilliams et al., 2015; Wright \& Christensen, 2010), the link between prosocial behaviour (Finkelstein et al., 2005; George \& Bettenhausen, 1990; Grant, 2008b, 2012), and altruism (Penner et al., 2005; Perry \& Hondeghem, 2008). The second track is interested in linking PSM to public management and administration research. Subsequently, studies in this area emphasize the testing and strengthening the PSM construct and its measurement, institutional assumptions, and the relationship between PSM and performance (Christensen et al., 2017). Other themes that are prominent in this track also include organizational context/setting (Cun, 2012; Steijn, 2008) and studies that purely focus on improving the practice of public management systems (Christensen et al., 2013; Kroll \& Vogel, 2013; Moynihan et al., 2012; Moynihan \& Pandey, 2010; Wright et al., 2012).

In line with improving public management systems, this study contributes to the second track of research on PSM by testing five of the subscales of the PSM construct on PMBPs of LGs in a developing country context. This is important because the literature on PSM is predominantly Western (Ritz et al., 2016), with only eleven (11) studies from Africa and ten (10) from South Africa, while $43.4 \%$ is concentrated in Europe, and 27.5\% from the USA (Ritz et al., 2016). Hence, testing the PSM scale in Ghana, which is in the Sub-Saharan Africa (SSA) region, will help strengthen the PSM theory and to validate the construct further.

The evidence on PSM suggests mixed findings. For example, previous research such as (Christensen et al., 2013; Cun, 2012; Kim \& Kang, 2016; Kim, 2006; Lee \& Choi, 2013; Steijn, 2008; Vandenabeele, 2014) found that there were significant differences in the effect size of the PSM scale on Korean public sector employees. These mixed findings are also evident in the 150 countries where the study administered the PSM scale (Christensen et al., 2013; Perry et al., 2010; Perry \& Hondeghem, 2008). As a result, the evidence reveals that contextual factors and the national culture of a country can influence the effect of employee PSM.

\subsection{Empirical research on the PSM construct}

The PSM construct is anchored on six main psychological motives (Perry, 1996; Vandenabeele, 2007) of public service employees: 1) the desire to take part in public policymaking by employees; 2) commitment to the public interest that is the perceived public value of work which seeks to 
benefit others; 3) civic duty, relates to the non-elected nature of public office holders; 4) social justice, demands that employees become equity sensitive in decision making especially towards minorities outside the organization; 5) compassion which requires public service post holders to be responsive to the needs of the groups who do not will political influence and 6) self-sacrifice demands that employees substitute personal gain or material reward for intangible rewards in the form of selfless service to the nation (Perry, 1996).

The evidence suggests that PSM influences employee task performance and affects the perception of the value of their work to the larger society (Moynihan et al., 2012; Wright et al., 2012). The literature indicates that PSM is positively related to employee performance (Christensen et al., 2013; Moynihan \& Pandey, 2010; Ritz, 2009), culture (Cun, 2012; GouldWilliams et al., 2015; Kim et al., 2012; Wright, Christensen \& Pandey, 2013), and commitment and job satisfaction (Cun, 2012; Homberg \& McCarthy, 2015; Vandenabeele, 2009). These findings suggest that employees with higher levels of PSM perform better than those with lower levels of PSM. Also, other studies find that higher levels of PSM are exclusively associated with only public employees (Bullock et al., 2015; Houston, 2000; Steijn, 2008; Vandenabeele, 2008). This evidence suggests that employees in public organizations tend to have higher scores on the PSM scale than employees in the private sector (Houston, 2000).

There is substantial information on how PSM relates to organizational and individual performance (Andersen et al., 2014; Christensen et al., 2013; Schott et al., 2015; Vandenabeele, 2009). However, little empirical evidence explains how PSM impacts the tools and processes that lead to organizational performance (Christensen et al., 2013; Kroll \& Vogel, 2013; Moynihan \& Pandey, 2010). Also, most of these studies focus on the developed world, with little research on developing countries, where contextual factors differ significantly.

\subsection{PSM and performance management practices (PMPs)}

PSM research is multidisciplinary and cuts across all organizational forms that seek to manage employee and organizational performance (Gabris \& Simo, 1995; Houston, 2000; Moynihan \& Pandey, 2007; Perry, 1996; Steijn, 2008). Current trends in the literature on organizational systems suggest that PSM influences the management practices of organizations (Ritz et al., 2016). The main assumption of PSM is that individual employees are predisposed to motives that focus on public service values, and employees are driven to work extra hard because they perceive that their work will have a social impact on the larger society (Bullock et al., 2015; Moynihan et al., 
2012). One fundamental gap in PSM research is whether or not the concept relates to organisations' internal business practices. While there have been few studies to this effect, the findings have been inconclusive and contextual (Moynihan et al., 2012). For instance, some Scholars have found links between PSM and public managers' use of PM in a sample of executive agencies of the US and the German local governments, respectively (Moynihan \& Pandey, 2010; Moynihan et al., 2012; Kroll \& Vogel, 2013).

Moynihan and Pandey's (2010) study indicates that PSM is an individual driver of managers' use of performance data for organizational decision-making. The study used a multi-method survey of 1538 senior managers in the US local government system and found that PSM is positively associated with performance information use, one of the best PM practices. The findings support that PSM is significantly related to behaviours contributing to high individual and organizational performance (Belle, 2013; Christensen et al., 2013; Kroll \& Vogel, 2013).

In another study, Moynihan et al. (2012) find that the perceived social impact of employees' work on the public relates to their use of performance information, especially with purposeful and political uses of the PM cycle. The implication is that public managers with high PSM levels use performance data for decision-making, such as promotion, program funding, etc. The study further observed that a unit increase in the perceived social impact of work corresponds with a unit increase of 0.42 on the type of performance data used: purposeful and political (Moynihan et al., 2012, p. 470). Similarly, several studies have found evidence to support the PSMperformance link. Other studies have also found that public sector employees with higher levels of PSM correlated with employee performance, meaningful work, person-job fit, and the desire to serve the public cause (Houston, 2000; Perry, 1996; Steijn, 2008).

The evidence supporting PSM and PMPs is inconclusive. For example, studies that attempt to link PSM with PMPs find that employees' perception of the social impact of their work may lead to their extra-role behaviour to use performance information for decision-making (Moynihan \& Pandey, 2010). These studies merely look at only information use, which is part of the performance review process, thereby offering little understanding of how PSM affects PMPs, a set of bundles implemented by top management to enhance individual and organizational performance. 


\subsection{The context of public service motivation in local government in Ghana}

This study examines four (4) PM dimensions: strategic planning (SP), performance monitoring \& evaluation (PME), performance review (PEREVIEW), and performance improvement (PERIMP) of metropolitan and municipal assemblies, and the links between these dimensions and employees' PSM levels in LGs. Perry and Hondegehem (2008) argue that testing the effect of PSM across different cultures is important in contributing to the reliability and theory-building of the PSM construct globally. At the same time, it will help public organizations explore its benefits to increase performance outcomes and productivity.

The test of the PSM construct in Ghana is less known. Hence, its evidence among local-level public managers is equally unknown. However, few studies have found evidence to support that PSM exists in the civil service in Ghana. However, no relationship exists between PSM levels and civil service employees' performance or output (Brenya, Adu-Gamfi, Kyei, Tariah, Nmerukini, Boateng \& Angmor, 2017). The study found that employees profess to have a sense of social justice, compassion, commitment to the public interest, self-sacrifice, and civic duty. However, they were unwilling to commit to the course of public service because of the poor conditions of services.

However, several studies on public sector motivation in the Ghanaian experience exist. Recent studies suggest that motivation in public sector organizations has largely been ineffective, and this accounts for the low productivity levels in the public service (Annan-Prah, \& Ohemeng, 2015). This is because the government has been unable to develop a strong motivational system for LG workers (Ayee, 2001; Antwi, 2009). The result of this failure has led to several industrial actions, thereby affecting productivity at the local level (Akudugu, 2013; Dodoo, 1997). The low morale among LG employees may be due to the poor compensation and reward systems found in the public service. The consequential effect is that many public programs have failed at the implementation stage, constraining local-level development (Ahenkan, Tenakwah \& Bawole, 2018; Ohemeng, 2009).

Many problems associated with PM practices in Ghana are the lack of technical competencies and an understanding of the PM system (Bawole et al., 2013; Biron et al., 2011). However, the mechanical aspects of the PM systems are too technical, and the information is often too detailed and not user-friendly (Biron et al., 2011). 
Also, research reveals that financial or external rewards have often failed to meet the demands of workers (Jacobsen et al., 2014; Koike, 2013), and relying heavily on extrinsic rewards systems may not be enough to bring about changes in employee and organizational performance (Jacobsen et al., 2014). Consequently, PSM is the framework that predicts a higher level of employee motivation and performance outcomes in the rapidly changing environment of public organizations in managing results at the local level (Moynihan \& Pandey, 2005). Suppose local government employees with higher levels of PSM adapt to these kinds of rational, norm-based and affective motives in their task performance. In that case, greater attention will be given to individual and organizational KPIs.

For this study, examining how individual PSM levels are measured by the five sub-scales: attraction to policymaking, commitment to the public interest, civic duty, compassion and self-sacrifice may influence PMBPs: SP, PME, PEREVIEW, and PERIMP. The study recognizes that PSM is rational, normative, and affective based (Perry, 1996) and investigates the combined connection between these three motives and the four dimensions of metropolitan and municipal assemblies' PMPs. From the above discussions, the study proposes the following hypotheses:

$\mathbf{H}_{1}$ : Employees with higher PSM levels will positively influence their LGs' PMPs. total PMP.

$\mathbf{H}_{2}$ : The combined PSM construct will be significantly associated with

\section{Methodology}

\subsection{Sample and study setting}

A total of 850 LG Employees in the Greater Accra Region (GAR) ${ }^{1}$ were part of this study. Out of the 850 questionnaires administered, only 725 responses were received, representing an $85.29 \%$ response rate. However, after screening and cleaning the data for missing values, only 441 responses were usable. Participation in the survey was voluntary, and respondents' confidentiality was protected. Respondents for the survey were current employees of Local Government Service (LGS) who were either full-time or part-time employees located in the GAR. The sample consisted of 178 females (40.4 per cent) and 263 males (59.6 per cent).

${ }^{1}$ Greater Accra Region is the National Capital of Ghana located in the coastal zone. 


\subsection{Data collection procedure}

This study is a cross-sectional survey in which the data was collected at one time. The survey questionnaire was self-administered between July and August 2017. The Office of the Head of Local Government Service (OHLGS)contacted participants for this study. An introductory letter was sent to the 11 metropolitans and municipal assemblies (MMAs) in the National Capital of Ghana. The respondents were personally contacted in their respective offices. The respondents were senior local government officers who have served between 1 and 20 years and above. Eight hundred fifty (850) survey questionnaires were randomly distributed to officers with the salary Grade Level 15 - Level $21^{2}$ in the 11 MMAs. The Established Warrant Levels $^{3}$ in the Controller and Accountant General's Integrated Personnel Payroll unit of the OHLGS were used to ensure that each element in the sample had an equal chance of being included in the study. A list of the 850 officers and their workplaces was written and further contacted directly to respond to the survey. All data were collected with the guidelines of the Local Government Service ethics and protocol ${ }^{4}$.

The study recognizes that PSM comprises rational, normative, and affective motives, using Perry's (1996) classification to test the connection between these three motives and the four bundles of metropolitan and municipal assemblies (MMAs) PMB practices. The study measured individual PSM levels using the five sub-scales for the motives above: attraction to policymaking, commitment to the public interest, civic duty, compassion, and self-sacrifice, while PMBPs bundles included SP, PME, PEREVIEW, and PERIMP.

The dependent variable, PMBP, was measured by four bundles: strategic planning, performance monitoring \& evaluation, performance review, and performance improvement. First, SP was measured using nine (9) items developed to capture the processes and activities of the PM process using previous studies (Ammons \& Roenigk, 2015). Respondents were asked to indicate whether their organizations engaged in the SP process before designing their performance indicators. A sample item on the SP scale is (my assembly conducts strategic planning). Items for the PME scale included four (4) items (My assembly has a routine monitoring plan). The PEREVIEW

\footnotetext{
${ }^{2}$ Levels 15-21 are senior entry grades for professional and non-professional classes in the Local Government Service in Ghana. These levels are considered as middle and managerial levels in practice. ${ }^{3}$ The established warrant level is the pay roll grades and structure used in the public service to pay employees with different qualifications and experience.

${ }^{4}$ The local Government Service ethics and protocol can be found on www.lgs.gov.gh under Service Protocol Menu.
} 
scale had three (3) items, which included (during performance reviews, my supervisor focuses on the results I should obtain). Eight (8) items were measured on the PERIMP scale, and a sample item is (my assembly has a routine performance improvement program for staff).

All four scales were measured using a 7-point Likert scale (1 strongly disagree to 7 strongly agree). For PMBP measurement, the four bundles were combined for this purpose, making twenty-four (24) items. The Cronbach alpha reliability result for PMBP for the 24 items was 0.94, which suggested high reliability for all the items (see Table 1).

The PSM construct was measured using Perry's (1996) three-based motives: rational, norm-based, and affective. These three motives were further divided into sub-indicators, namely: attraction to policymaking (ATTRACT), commitment to the public interest (COMM), (rational motives), civic duty (CID) (norm-based motive), and compassion (COMP) and self-sacrifice (SS) (affective motives). All five items from the original scale were used for the ATTRACT scale, and a sample item included PSM11 (politics is a good word). The COMM scale was measured using four (4) items, including PSM30 (meaningful public service is essential to me). Also, the CID scale was measured by five items, and a sample item included PSM21 (I am willing to go to great lengths to fulfil my obligations to my country).

In contrast, COMP was measured using all eight items from the original scale, and a sample item included PSM2 (the plight of the underprivileged often moves me). The SS scale was measured with five items, including PSM1 (making a difference in society means more to me than personal achievements). For total PSM, a combined 27 items from the five scales were used to observe the total effect of PSM on the dependent variable.

All five scales were measured on a 7-point Likert-type scale ranging from 1 (strongly disagree) to 7 (strongly agree). Except for the (attraction to policymaking) scale, which had a Cronbach alpha of 0.68 , the rest had a reliability test above 0.7 . The Cronbach alpha for the PSM scale in this sample was 0.94, which is robust compared with previous studies (Moynihan \& Pandey, 2010). Table 1 depicts the individual reliability test for all the scales in this study. 
Table 1. Results of individual scales reliability test

\begin{tabular}{llll}
\hline Variable & Cronbach alpha $(\alpha)$ & No. of items & N \\
\hline PMBP sub-scales & & & \\
SP & 0.90 & 9 & 425 \\
PME & 0.82 & 4 & 437 \\
PEREVIEW & 0.83 & 3 & 438 \\
PERIMP & 0.93 & 8 & 429 \\
PMPs & 0.94 & 24 & 407 \\
& & & \\
PSM sub-scales & & & \\
ATTRACT & 0.68 & 5 & 427 \\
COMM & 0.89 & 4 & 440 \\
CID & 0.85 & 5 & 440 \\
COMP & 0.89 & 8 & 428 \\
SS & 0.88 & 5 & 435 \\
PSM & 0.94 & 27 & 411 \\
\hline
\end{tabular}

\section{Results and discussions}

The results of the descriptive statistics include means, standard deviations, and bivariate correlations for all the variables provided in Table 2.

\subsection{Bivariate correlations}

The first hypothesized relationship was between the four bundles of PMBPs of LGs: SP, PME, PEREVIEW, and PERIMP, and their employees' PSM levels. As predicted, there were significant correlations between SP and employees' PSM levels, $\mathrm{r}=0.51(\mathrm{p}<0.01)$, PME, $\mathrm{r}=0.43(\mathrm{p}<0.01)$, PEREVIEW, $r=0.21(\mathrm{p}<0.01)$, and PERIMP, $r=0.32(\mathrm{p}<0.01)$. Employees with high PSM scores were significantly more likely to report that their organizations engaged in SP, PME, PEREVIEW, and PERIMP. Except for SP, which correlated at 0.3 , the other three had moderate correlations.

While these results seem to support the bivariate relationships between these variables, further analysis through collinearity diagnoses using SPSS revealed that the degree of collinearity evident in the data was not detrimental to the findings (Hair et al., 1998; Pallant, 2011). The largest variance inflation factor (VIF) was not greater than ten, and the tolerance statistics were greater than 0.2 , suggesting that no strong linear relationship exists between the variables and, accordingly, no major violations of the assumptions of the inferential statistics used.

For the multicollinearity test in this study, the variables were unaffected because most correlated lower than 0.70 (Tabachink \& Fidell, 2014). Also, the PSM scales are highly correlated with total PSM, further 
validating Perry's (1996) construct reliability since all the five indicators measure the same thing, thus, employees' PSM levels. Nonetheless, no major multicollinearity was present in the data except for CID \& COMP; and COMP $\&$ SS, which had correlations above 0.7 ( 0.77 and 0.79 , respectively). Additionally, the results showed that the correlations between the four bundles of PMBPs suggest no significant collinearity. Hence, hypothesis 1 is supported.

Table 2. Descriptive and bivariate analysis

\begin{tabular}{|c|c|c|c|c|c|c|c|c|c|c|c|}
\hline Variable & Mean & $\mathrm{SD}$ & 1 & 2 & 3 & 4 & 5 & 6 & 7 & 8 & $\begin{array}{ll}10 & 11\end{array}$ \\
\hline SP & 47.23 & 7.62 & 1 & & & & & & & & \\
\hline PME & 18.10 & 3.47 & $0.69^{* *}$ & 1 & & & & & & & . \\
\hline PERVIEW & 11.70 & 3.27 & $0.37^{* *}$ & $0.54^{* *}$ & 1 & & & & & & \\
\hline PERIMP & 37.59 & 9.76 & $0.46^{* *}$ & $0.51^{* *}$ & $0.64^{* *}$ & 1 & & & & & \\
\hline PSM & 112.35 & 16.63 & $30.51^{* *}$ & $0.43^{* *}$ & $0.21^{* *}$ & $0.32^{* *}$ & 1 & & & & \\
\hline ATTRACT & 22.33 & 4.08 & $0.34^{* *}$ & $0.32^{* *}$ & $0.14^{* *}$ & $0.14^{* *}$ & $0.67^{* *}$ & 1 & & & \\
\hline COMM & 19.37 & 3.33 & $0.49^{* *}$ & $0.36^{* *}$ & $0.11^{*}$ & $0.26^{* *}$ & $0.78^{* *}$ & $0.59^{* *}$ & 1 & & \\
\hline CID & 24.57 & 4.43 & $0.47^{* *}$ & $0.39^{* *}$ & $0.18^{* *}$ & $.294^{* *}$ & $0.88^{* *}$ & $0.44^{* *}$ & $0.64^{* *}$ & 1 & \\
\hline COMP & 41.24 & 7.37 & $0.41^{* *}$ & $0.35^{* *}$ & $0.23^{* *}$ & $.305^{* *}$ & $0.89^{* *}$ & $0.37^{* *}$ & $0.54^{* *}$ & $0.77^{* *}$ & 1 \\
\hline SS & 24.21 & 4.84 & $0.41^{* *}$ & $0.36^{* *}$ & $0.17^{* *}$ & $0.29^{* *}$ & $0.81^{* *}$ & $0.404^{* *}$ & * $0.59^{* *}$ & $0.71^{* *}$ & $0.79^{* * *} 1$ \\
\hline $\begin{array}{l}\text { Total } \\
\text { PMBP }\end{array}$ & 86.42 & 13.81 & $10.89^{* *}$ & $0.86^{* *}$ & $0.69^{* *}$ & $0.71^{* *}$ & $0.51^{* *}$ & $0.32^{* *}$ & $0.43^{* *}$ & $0.45^{* *}$ & $0.42^{* *} 0.41^{* *} 1$ \\
\hline
\end{tabular}

The second hypothesized relationship in the model was between the total PSM and PMBP of LGs. Table 2 highlights significant variations in how the five PSM scales affect the PMBP of LGs and their employees' PSM levels. There were significant relationships between employees' scores on ATTRACT and total PM best practices of LGs, $r=0.32(\mathrm{p}<0.01)$, COMM, $\mathrm{r}=0.43(\mathrm{p}<0.01), \mathrm{CID}, \mathrm{r}=0.45(\mathrm{p}<0.01)$, COMP, $\mathrm{r}=0.42(\mathrm{p}<0.01)$, and $\mathrm{SS}, \mathrm{r}=0.41(\mathrm{p}<0.01)$. This implies that employees rating themselves higher on the five subscales of PSM were more likely to report that their organization's performance management practices were effective, providing significant support for hypothesis 2 . 


\subsection{Regression analyses}

Based on the significant bivariate relationships indicated in Table 2 above, multiple regression analysis was performed to examine the combined effect of the univariate effect of the five scales of the PSM construct as independent variables on the outcome variable PMP (Tabachnick \& Fidell, 2014) as the first model, and to test the combined effect of the total PSM on the four individual bundles of the PMP scales as the second model. Multiple regression analysis also accounts for the inter-correlations between the five PSM scales in Table 2 above (Tabachnick \& Fidell, 2014).

The results showed that the hypothesized relationships in the first model indicate that employees' ATTRACT, COMM, CID, COMP, and SS scores should all predict PMP. All five PSM scales were entered into the regression equation as independent variables in the first model. Combined PMBP was included in the model as a dependent variable. In Table 3, the combined relationship between the five indicators of PSM on PMP was statistically significant $F(5,375)=25.607, p<0.0005$, and contributed 25.5 per cent of the variation in the PMP. The Beta weight for the following variables was not statistically significant: ATTRACT $(r=0.07, \mathrm{~ns})$, COMP $(\mathrm{r}=0.12, \mathrm{~ns})$, and SS $(\mathrm{r}=0.05, \mathrm{~ns})$, suggesting that only $\operatorname{COMM}(\mathrm{r}=0.19, \mathrm{p}$ $<0.005)$ and $\operatorname{CID}(\mathrm{r}=0.18, \mathrm{p}<0.05)$ contributed to the variation in combined PMP (see Table 3).

Table 3. Regression results for PMPs as a single dependent variable

\begin{tabular}{lllll}
\hline & B & Std. Error & $\beta$ & Sig \\
\hline ATTRACT & 0.236 & 0.187 & 0.070 & 0.209 \\
COMM & 0.770 & 0.270 & 0.186 & $0.005^{* * *}$ \\
CID & 0.560 & 0.240 & 0.179 & $0.021^{*}$ \\
COMP & 0.220 & 0.150 & 0.120 & 0.150 \\
$\mathrm{SS}$ & 0.142 & 0.220 & 0.050 & 0.520 \\
$\mathrm{~N}=380 ; \mathrm{F}=25.607^{* * *}$ & & & \\
$\mathrm{R}^{2}=0.255 ;$ Adjusted $\mathrm{R}^{2}=0.245$ & & & \\
${ }^{*} \mathrm{p}<0.05 ; * * * \mathrm{p}<0.001 ;$ Dependent: PMPs = performance management practices. \\
\multicolumn{4}{r}{ Source: Prepared by authors, based on SPSS V.22 output } \\
\end{tabular}

The study further examined the combined effect of the PSM construct as a single independent variable on the four bundles of PMBP: SP, PME, PEREVIEW, and PERIMP as separate dependent variables. The hypothesized relationships, ATTRACT, COMM, CID, COMP, and SS, were entered in the first model as independent variables, and SP was included as the dependent variable. The results from Table 4 show that the combined relationship between ATTRACT, COMM, CID, COMM, and SS on SP was 
statistically significant $F(5,390)=31.354, p<0.001$ and accounted for 28.7 per cent of the variance in SP. The Beta coefficients for ATTRACT $(r=0.05$, $\mathrm{ns}), \operatorname{COMP}(\mathrm{r}=0.05, \mathrm{~ns})$ and SS $(0.04, \mathrm{~ns})$ were not statistically significant, indicating that only $\operatorname{COMM}(\mathrm{r}=0.28, \mathrm{p}<0.001)$ and $\operatorname{CID}(\mathrm{r}=0.20, \mathrm{p}<0.001)$, contributed most to explain the total variance in SP. Additionally, to observe the effect of the five scales of the PSM construct on PME, the regression results in the second model showed that the five scales were statistically significant $\mathrm{F}(5,402)=16.549, \mathrm{p}<0.001$ and could only explain 17.1 per cent of the variance in the dependent variable (PME). The standardized beta coefficients for the two of the scales: ATTRACT $(r=0.16)$ and CID $(r=0.16)$, were statistically significant, while COMM $(r=0.04, n s), \operatorname{COMP}(r=0.07$, $\mathrm{ns})$, and $\mathrm{SS}(\mathrm{r}=0.09, \mathrm{~ns})$ were not significant.

Also, the third model showed that the Beta weights for three indicators of PSM: COMM ( $\mathrm{r}=-0.08$, ns), CID $(\mathrm{r}=0.05$, ns $)$, and SS $(\mathrm{r}=-0.04)$ were not significant, whereas ATTRACT $(r=0.11, \mathrm{p}<0.01)$ and COMP $(r=0.23$, $\mathrm{p}<0.01)$ were statistically significant at $10 \%$. The total variance explained in the dependent variable, PERIMP was only 6.5 per cent. The fourth regression model shows that the hypothesized relationships for all five scales were not statistically significant. Employees who rated themselves higher on the five scales of the PSM construct were more likely to report that their LGs were not engaged in performance improvement practices. Although this finding confirms previous studies on LG PM practices (Moynihan et al., 2012), the finding must be interpreted cautiously because other contextual factors may account for this. The five scales contributed about 11.8 per cent of the variance in PERIMP as the dependent variable. However, the overall model was significant $F(5,394)=10.578, p<0.001$.

Furthermore, the hypothesized relationship that total PSM levels of employees should predict employees' LGs PMBPs was supported in this study. Table 4 shows that the effect of total PSM on combined PMPs was statistically significant $F(1,379)=124.427, p<0.001$, contributing 24.7 per cent of the variance. The standardized Beta weight for total PSM was statistically significant $(r=0.49, p<0.001)$, thus explaining the changes in combined PMPs. 
Table 4. Regression results of the relationship between PSM sub-measures and PMBP submeasures

\begin{tabular}{|c|c|c|c|c|c|c|c|c|c|}
\hline Model & Variable & B & SE B & $\beta$ & $\mathrm{R}^{2}$ & Adj. $R^{2}$ & $\mathrm{~F}$ & $\mathrm{~N}$ & $\begin{array}{l}\text { Dependent } \\
\text { variable }\end{array}$ \\
\hline \multirow{5}{*}{1} & ATTRACT & 0.10 & 0.09 & 0.05 & \multirow{5}{*}{0.287} & \multirow{5}{*}{0.278} & \multirow{5}{*}{$31.354 * * *$} & \multirow{5}{*}{395} & \multirow{5}{*}{$\mathrm{SP}$} \\
\hline & COMM & 0.63 & 0.14 & $0.28 * * *$ & & & & & \\
\hline & CID & 0.35 & 0.13 & $0.20 * * *$ & & & & & \\
\hline & COMP & 0.06 & 0.08 & 0.05 & & & & & \\
\hline & $\mathrm{SS}$ & 0.07 & 0.12 & 0.04 & & & & & \\
\hline \multirow{5}{*}{2} & ATTRACT & 0.14 & 0.05 & $0.16 * * *$ & \multirow{5}{*}{0.171} & \multirow{5}{*}{0.160} & \multirow{5}{*}{$16.549 * * *$} & \multirow{5}{*}{407} & \multirow{5}{*}{ PME } \\
\hline & COMM & 0.04 & 0.07 & 0.04 & & & & & \\
\hline & CID & 0.12 & 0.06 & $0.16 * * *$ & & & & & \\
\hline & COMP & 0.03 & 0.04 & 0.07 & & & & & \\
\hline & SS & 0.06 & 0.05 & 0.09 & & & & & \\
\hline \multirow{5}{*}{3} & ATTRACT & 0.08 & 0.05 & $0.11 * *$ & \multirow{5}{*}{0.065} & \multirow{5}{*}{0.054} & \multirow{5}{*}{$5.643 * *$} & \multirow{5}{*}{408} & \multirow{5}{*}{ PEREVIEW } \\
\hline & COMM & -0.08 & 0.07 & -0.08 & & & & & \\
\hline & CID & 0.04 & 0.06 & 0.05 & & & & & \\
\hline & COMP & 0.11 & 0.04 & $0.23 * *$ & & & & & \\
\hline & SS & -0.03 & 0.06 & -0.04 & & & & & \\
\hline \multirow{5}{*}{4} & ATTRACT & -0.10 & 0.14 & -0.04 & \multirow{5}{*}{0.118} & \multirow{5}{*}{0.107} & \multirow{5}{*}{$10.578 * * *$} & \multirow{5}{*}{399} & \multirow{5}{*}{ PERIMP } \\
\hline & COMM & 0.32 & 0.20 & 0.11 & & & & & \\
\hline & CID & 0.21 & 0.18 & 0.09 & & & & & \\
\hline & COMP & 0.17 & 0.12 & 0.13 & & & & & \\
\hline & SS & 0.20 & 0.16 & 0.08 & & & & & \\
\hline 5 & Total PSM & 0.41 & 0.37 & 0.49 & 0.247 & 0.245 & $124.427 * * *$ & 380 & PMBP \\
\hline
\end{tabular}

The hypotheses were developed to show that LGs' PM best practices are partly influenced by their employees' PSM levels measured by three main motives that compel them to join LGs. The first motive that compels and explains why employees choose to work with public institutions is based on rationality. With this motive, employees are attracted to LGs' policymaking processes and view their presence there as contributing to protecting the public interest. The second motive involves normative assumptions of institutions. The norm-based motive is premised on the assumption that organizations exist to perform a communal duty to society. Therefore, employees help their LGs achieve their core mandate and mission by fulfilling this motive.

Moreover, the third motive is that LGs employees' behaviours are influenced by affective feelings where employees see their service to the larger social system above their interests. LG employees believe that this 'call to service' and the perceived impact of their work transcend beyond their immediate environment. The focus of affective motives measured by compassion and self-sacrifice is for employees to see the social benefits of 
their work to minorities and the less privileged at the local level. This study examined PSM at five levels to give a clearer picture of the unique contributions of each scale on PMBPs, and how employees' PSM levels can influence these bundles.

$\mathrm{H}_{1}$ examined the relationship between employees' scores on the individual scales of the PSM construct and the combined PMPs of their LGs, and the results showed that they were correlated. Although this relationship has been empirically demonstrated in many studies (Andersen et al., 2014; Christensen et al., 2017; Homberg \& McCarthy, 2015; Moynihan \& Pandey, 2007), the results demonstrate that the mixed findings identified in previous studies of the PSM construct might have been due to factors specific to the context or the setting (Kim et al., 2012; Perry \& Hondeghem, 2008; Vandenabeele, 2008).

We found that ATTRACT, COMM, CID, COMP, and SS correlate with the four PMP scales in the Ghanaian LG system. Further regression analysis revealed that compassion and self-sacrifice did not contribute any unique variance to the prediction of combined PMP in our LG sample. This finding provides further evidence to support Cun (2012), Perry \& Hondeghem (2008), and Kim et al. (2012) findings that employees' PSM levels are influenced by organizational setting, socialization process, and culture and hence. This finding may require further testing in different organizational settings in the Ghanaian experience to conclude.

$\mathrm{H}_{2}$ indicated a positive and significant effect on total employees' PSM levels and the combined PMP of LGs. Overall, the results support the findings of Moynihan et al. (2012) and Kroll \& Vogel (2013), who found that public managers' PSM levels were significantly associated with performance information used by federal governments. Performance information use is a key component of a PM system. Hence, the combined effect of the PSM construct was significant, contributing about 24.7 per cent to explain the variance in PMP of LGs in this sample. This study may suggest that the PSM scores of employees are important in determining the effectiveness of LGs PM best practices. For example, LGs may vary the PM process by relying on employees with higher levels of PSM to encourage and lead the change process, especially in new performance regimes in developing country contexts. However, the absence of the significant contributions of compassion and self-sacrifice as separate variables on PMP in this sample may require further analysis. The two scales constitute the highest scores on the PSM construct (Perry, 1996). However, this sample showed no significant effect of the two on PMP. The implication is that PSM is suitable for predicting relationships when used as a single construct (Perry et al., 2010). Nonetheless, 
this finding may require further research with different samples and in a different organizational setting to conclude (Cun, 2012; Kim et al., 2012).

The implications of this research for practitioners in LGs indicate that management practices should be rational and normative to elicit positive employee behaviour in public organizations. Subsequently, increasing LG activities that encourage and release employees' rational and norm-based motives through ATTRACT, COMM, and CID is associated with positive outcomes of their PMBPs which is important for overall organizational performance (Vandenabeele, 2009). LGs should seek to reinforce their employees' COMP and SS behaviour, leading to effective outcomes on management practices such as strategic planning, PME, PEREVIEW, and PERIMP. Further, LGs should develop frameworks that allow every employee to take part in the strategic formulation of organizational goals and participate in the policymaking and implementation process at the local level.

\section{Conclusion}

The study had a cross-sectional design with data collected only from one LG administrative region involving 11 MMAs in the national capital. To compensate for the potential of common response bias and address the study's limitations, we randomly distributed the sample size among the 11 MMAs. Using a single geographical region of LG employees can limit common source bias. Since this is an exploratory study, there is a need to expand the cases to other regions to see whether the same results will be attained. However, in particular, LG in the GAR appears to have different incentives than those in other regions or even poor LGs, which forestalls any deficiency.

Our study contributes to the literature on the relationship between PSM and PMPs by finding that higher PSM levels are significantly associated with increases in LG PMPs. The findings also confirmed that PSM is more related to the rational motives of employees than affective motives in most cultures (Christensen et al., 2017; Cun, 2012; Kim et al., 2012). While previous studies have provided evidence to support that PSM is positively related to performance information use (Moynihan et al., 2012), our research is one of its kind to test the PSM variable on the four bundles of PMBP. Hence, this finding requires further studies in similar and different settings to test the relationship between PSM and the PMP bundles of LGs. Of particular interest will be to test the relationship between national culture and employee PSMs levels on the PMP of LGs.

This study suggested that PSM plays an important role in the study of PMBP. While the results may hold brief for the Ghanaian experience, they may have different implications for different contexts. Further studies should 
be conducted on the PSM construct on the four bundles of PMP as a single independent variable to support theory building, as the individual treatment of the construct has yielded no significant impact on the dependent variable. In contrast, we believe future research should be undertaken on the PSM as a single construct (Perry \& Hondeghem, 2008; Christensen et al., 2017). The cultural component of PSM should be addressed to strengthen theory building by including a cultural dimension of both PMPs and the PSM construct since some cultures may support higher organizational management practices than others.

\section{Declaration of conflicting interests}

The author(s) declared no potential conflicts of interest with respect to the research, authorship, and/or publication of this article.

\section{References}

Abane, J. A., \& Phinaitrup, B. (2017). Performance Management as an Alternative Tool for Local Governance: Evidence from Ghanaian Local Government Sector. International Journal of Human Resource Management Studies, 7(3), 188-209. https://doi.org/10.5296/ijhrs.v7i3.11532

Ahenkan, A., Tenakwah, E.S. \& Bawole, J. N. (2018). Performance Management Implementation Challenges in Ghana's Local Government System: Evidence from a Municipal Assembly. International Journal of Productivity and Performance Management, 67(3), 519-535. https://doi.org/: https://doi.org/10.1108/IJPPM-062016-0124

Akudugu, J. A. (2013). Inducing Local Government Performance in Ghana: The Case of the District Development Facility. International Journal of Asian Social Science, 3(6), 1402-1417.

Amirkhanyan, A. A., Kim, H. J. \& Lambright, K. T. (2013). The performance puzzle: Understanding the factors influencing alternative dimensions and views of performance. Journal of Public Administration Research and Theory, 24(1), 1-34. https://doi.org/10.1093/jopart/mut021

Ammons, D N, \& Rivenbark, W. C. (2008). Factors influencing the use of performance data to improve municipal services: Evidence from the North Carolina Benchmarking Project. Public Administration Review, 68(2), 304-318. https://doi.org/10.1111/j.15406210.2007.00864.x

Ammons, David N, \& Roenigk, D. J. (2015). Performance Management in Local Government: Is Practice Influenced by Doctrine? Public Performance \& Management Review, 38(3), 514-541. https://doi.org/10.1080/15309576.2015.1006461

Andersen, L. B., Heinesen, E., \& HolmPedersen, L. (2014). How does public service motivation among teachers affect student performance in schools? Journal of Public Administration Research and Theory, 24(3). https://doi.org/10.1093/jopart/mut082 
Annan-prah, E. \& Ohemeng, F. L. K. (2015). Improving Productivity through Performance Management in Public Sector Organizations in Ghana: Is Change Management the Answer? Lecturer and PhD. Candidate Department of Management Studies School of Business College of Humanities and Legal Studies Univer. April 2015.

Antwi, B. K. (2009). Renewing the Holy Grail of human motivation in the delivery of public service. Journal of Management Development, 28(6), 504-512. https://doi.org/10.1108/02621710910959666

Armstrong, M., \& Baron, A. (2007). Managing Performance: Performance Management in action (3rd ed.). Charted Institute of Personnel \& Development.

Ayee, J. R. A. (2001). Civil Service Reform in Ghana: A Case Study of Contemporary Reform Problems in Africa. African Journal of Political Science, 6(1), 1-41. https://doi.org/10.4314/ajps.v6i1.27319

Baird, K., Schoch, H. \& Chen, Q. J. (2012). Performance management system effectiveness in Australian local government. Pacific Accounting Review, 24(2), 161-185. https://doi.org/10.1108/01140581211258461

Belle, N. (2013). Experimental Evidence on the Relationship between Public Service Motivation and Job Performance. Public Administration Review, 73(1), 143-153. https://doi.org/10.1111/j.1540-6210.2012.02621.x

Biron, M., Farndale, E., \& Paauwe, J. (2011). Performance management effectiveness: lessons from world-leading firms. The International Journal of Human Resource Management, 22(6), 1294-1311. https://doi.org/10.1080/09585192.2011.559100

Boyne, G. A. (2002). Concepts and indicators of local authority performance: an evaluation of the statutory frameworks in England and Wales. Public Money \& Management, 22(2), 17-24. https://doi.org/10.1111/1467-9302.00303

Bozeman, B., \& Su, X. (2015). Public Service Motivation Concepts and Theory: A Critique. Public Administration Review, 75(5), 700-710. https://doi.org/10.1111/puar.12248

Brenya, E., Adu-Gyamfi, S., Kyei, E. Y., Tariah, F. P., Nmerukini, A., Boateng, E. K. \& Angmor, R. Y. (2017). Public service motivation in Ghanaian Civil Service: A case study of Ejusi-Juabebg Municipality. International Journal of Public Administration, 40(2), 164-175. https://doi.org/10.1080/01900692.2015.1089443

Brief, A. P. \& Motowildlo, S. J. M. (1986). Prosocial Organizational Behaviors. Academy of Management Review, 11(4), 710-725. https://doi.org/10.2307/258391

Bullock, J. B., Stritch, J. M., \& Rainey, H. G. (2015). International Comparison of Public and Private Employees' Work Motives, Attitudes, and Perceived Rewards. Public Administration Review, 75(3), 479-489. https://doi.org/10.1111/puar.12356

Campbell, J. W., Lee, H., \& Im, T. (2016). At the Expense of others: Altruistic helping behavior, performance management and transformational leadership. Public Management Review, 18(6). https://doi.org/10.1080/14719037.2015.1045018

Cavalluzzo, K. S., \& Ittner, C. D. (2004). Implementing performance measurement innovations: evidence from government. Accounting, Organizations and Society, 29(3-4), 243-267. https://doi.org/10.1016/S0361-3682(03)00013-8

Christensen, R. K., Paarlsberg, L., \& Perry, J. L. (2017). Public Service Motivation Research: Lessons for Practice. Public Administration Review, 77(4), 529-542. https://doi.org/10.1111/puar.12796 
Christensen, R. K., Whiting, S. W., Im, T., Rho, E., Stritch, J. M., \& Park, J. (2013). Public Service Motivation, Task, and Non-task Behavior: A Performance Appraisal Experiment with Korean MPA and MBA Students. International Public Management Journal, 16(1). https://doi.org/10.1080/10967494.2013.796257

Cun, X. (2012). Public service motivation and job satisfaction, organizational citizenship behavior. Chinese Management Studies, 6(2), 330-340. https://doi.org/10.1108/17506141211236758

Dahling, J. J., \& O'Malley, A. L. (2011). Supportive Feedback: Environments Can Mend Broken Performance Management Systems: The College of New Jersey. Industrial and Organizational Psychology, 4, 201-203. https://doi.org/10.1111/j.17549434.2011.01327.x

Dewettinck, K., \& van Dijk, H. (2013). Linking Belgian employee performance management system characteristics with performance management system effectiveness: exploring the mediating role of fairness. The International Journal of Human Resource Management, 24(4), 806-825. https://doi.org/10.1080/09585192.2012.700169

Dodoo, R. (1997). Performance standards and measuring performance in Ghana. Public Administration and Development, 17(1), 115-121. https://doi.org/10.1002/(SICI)1099-162X(199702)17:1\%3C115::AIDPAD908\%3E3.0.CO;2-P

Favero, N., Meier, K. J., \& O'Toole, L. J. (2016). Goals, Trust, Participation, and Feedback: Linking Internal Management with Performance Outcomes. Journal of Public Administration Research and Theory, 26(2). https://doi.org/10.1093/jopart/muu044

Finkelstein, M. A., Penner, L. A., \& Brannick, M. T. (2005). Motive, Role Identity, and Prosocial Personality as Predictors of Volunteer Activity. Social Behavior and Personality: An International Journal, 33(4), 403-418. https://doi.org/10.2224/sbp.2005.33.4.403

Francois, P. (2000). Public Service Motivation' as an Argument for Government Provision. Journal of Public Economics, 78(3), 275-299. https://doi.org/10.1016/S00472727(00)00075-X

Gabris, G. T., \& Simo, G. (1995). PSM as a variable in employment decision. Public Personnel Management, 24, 33-51.

George, J. M., \& Bettenhausen, K. (1990). Understanding prosocial behavior, sales performance, and turnover: A group-level analysis in a service context. Journal of Applied Psychology, 75(6), 698-709. https://doi.org/10.1037/0021-9010.75.6.698

Gill, P. J. \& Carter, S. L. (2016). Graphic Feedback, Performance Feedback, and Goal Setting Increased Staff Compliance with a Data Collection Task at a Large Residential Facility. Journal of Organizational Behavior Management, 36(1), 56-70. https://doi.org/http://dx.doi.org/10.1080/01608061.2016.1152207

Gould-Williams, J. S., Mostafa, A. M. S., \& Bottomley, P. (2015). Public service motivation and employee outcomes in the Egyptian public sector: Testing the mediating effect of person-organization fit. Journal of Public Administration Research and Theory, 25(2). https://doi.org/10.1093/jopart/mut053

Grant, A. M. (2008a). Does intrinsic motivation fuel the prosocial fire? Motivational synergy in predicting persistence, performance, and productivity. Journal of Applied 
Psychology, 93(1), 48-58. https://doi.org/10.1037/0021-9010.93.1.48

Grant, A. M. (2008b). Does intrinsic motivation fuel the prosocial fire? Motivational synergy in predicting persistence, performance, and productivity. The Journal of Applied Psychology, 93(1), 48-58. https://doi.org/10.1037/0021-9010.93.1.48

Grant, A. M. (2012). Leading with Meaning: Beneficiary Contact, Prosocial Impact, and the Performance Effects of Transformational Leadership. Academy of Management Journal, 55(2), 458-476. https://doi.org/10.5465/amj.2010.0588

Hair, J., Jr., Rolph, E., Anderson, Tatham, R. \& Black, W. (1998). Multivariate Data Analysis. Prentice-Hall.

Halachmi, A. (2002). Performance measurement, accountability, and improved performance. Public Performance and Management Review, 25(4), 370-374. https://doi.org/10.2307/3381131

Hawke, L. (2012). Australian public sector performance management: success or stagnation? International Journal of Productivity and Performance Management, 61, 310-328. https://doi.org/10.1108/17410401211205669

Homberg, F., \& McCarthy, D. (2015). A meta-analysis of the relationship between public service motivation and job satisfaction. Public Administration Review, 75(5), 711-722. https://doi.org/10.1111/puar.12423

Hoontis, P., \& Kim, T. (2012). Antecedents to Municipal Performance Measurement Implementation. Public Performance \& Management Review, 36(1), 158-173. https://doi.org/10.2753/PMR1530-9576360108

Houston, D. J. (2000). Public Service Motivation: A Multivariate test. Journal of Public Administration Research and Theory, (4), 713-728. https://doi.org/10.1093/oxfordjournals.jpart.a024288

Jacobsen, C. B., Hvitved, J., \& Andersen, L. B. (2014). Command and motivation: How the perception of external interventions relates to intrinsic motivation and public service motivation. Public Administration, 92(4). https://doi.org/10.1111/padm.12024

Kim, Y. \& Kang, M. (2016). The Performance Management System of The Korean Healthcare Sector: Development, Challenges, and Future Tasks. Public Performance \& Management Review, 24(1), 297-315. https://doi.org/10.1080/15309576.2015.1108771

Kim, S. (2006). Public service motivation and organizational citizenship behavior in Korea. International Journal of Manpower, 27(8), 722-740. https://doi.org/10.1108/01437720610713521

Kim, S., Vandenabeele, W., Wright, B. E., Andersen, L. B., Cerase, F. P., Christensen, R. K., Desmarais, C., Koumenta, M., Leisink, P., Liu, B., Palidauskaite, J., Pedersen, L. H., Perry, J. L., Ritz, A., Taylor, J., \& De Vivo, P. (2012). Investigating the structure and meaning of public service motivation across populations: Developing an international instrument and addressing issues of measurement invariance. Journal of Public Administration Research and Theory, 23(1), 79-102. https://doi.org/10.1093/jopart/mus027

Koike, O. (2013). Institutionalizing performance management in Asia: looking East or West? International Journal of Public Sector Management, 26(5), 347-360. https://doi.org/10.1108/IJPSM-05-2013-0066 
Kroll, A., \& Vogel, D. (2013). The PSM-Leadership Fit: A Model of Performance Information Use. Public Administration, 92(4), 974-991. https://doi.org/10.1111/padm.12014

Lee, C. D. (2005). Rethinking the goals of your performance-management system. Employment Relations Today Wiley, 32(3), 53-60. https://doi.org/10.1002/ert.20075

Lee, G., \& Choi, D. L. (2013). Does Public Service Motivation Influence the College Students' Intention to Work in the Public Sector? Evidence from Korea. Review of Public Personnel Administration, 36(2), 145-163. https://doi.org/10.1177/0734371X13511974

Lynggaard, M., Pedersen, M. J., \& Andersen, L. B. (2018). Exploring the Context Dependency of the PSM-Performance Relationship. Review of Public Personnel Administration, 38(3). https://doi.org/10.1177/0734371X16671371

Maley, J. (2014). Sustainability: the missing element in performance management. AsiaPacific Journal of Business Administration, 6(3), 190-205. https://doi.org/10.1108/APJBA-03-2014-0040

Mmieh, F., Mordi, C., Singh, S., \& Asiedu-Appiah, F. (2011). Performance Management in Public Sector Enterprises: A Case Analysis of Employees' Perceptions in the Electricity Company of Ghana (ECG). Journal of African Business, 12(July 2014), 419-438. https://doi.org/10.1080/15228916.2011.621847

Moynihan, D. P., Pandey, S. K., \& Wright, B. E. (2012). Prosocial Values and Performance Management Theory: Linking Perceived Social Impact and Performance Information Use. Governance-an International Journal of Policy Administration and Institutions, 25(3), 463-483. https://doi.org/10.1111/j.1468-0491.2012.01583.x

Moynihan, Donald P., \& Pandey, S. K. (2010). The big question for performance management: Why do managers use performance information? Journal of Public Administration Research and Theory, 20(4), 849-866. https://doi.org/10.1093/jopart/muq004

Moynihan, Donald P, \& Pandey, S. K. (2007). The Role of Organizations in Fostering Public Service Motivation. Public Administration Review, 67(1), 40-53. https://doi.org/10.1111/j.1540-6210.2006.00695.x

Moynihan, Donald P. \& Pandey, S.K. (2005). Why and how do state governments adopt and implement "managing for results" reforms? Journal of Public Administration Research and Theory, 15(2), 219-243. https://doi.org/10.1093/jopart/mui012

Nielsen, P. A. (2014). Learning from performance feedback: Performance information, aspiration levels, and managerial priorities. Public Administration, 92(1). https://doi.org/10.1111/padm.12050

Nurkholis, Mohamad, S. H. M. \& \& Ismail, S. (2014). The effect of regulation and goal orientation on performance measurement utilization: Evidence from Indonesian local governments. Asian Journal of Business and Accounting, 7(1), 81-105.

Ohemeng, F. L. (2011). Institutionalizing the Performance Management System in Public Organizations in Ghana. Public Performance \& Management Review, 34(4), 467-488. https://doi.org/10.2753/PMR1530-9576340402

Ohemeng, F. L. K. (2009). Constraints in the Implementation of Performance Management Systems in Developing Countries: The Ghanaian Case. International Journal of Cross- 
Cultural Management, 9(1), 109-132. https://doi.org/10.1177/1470595808101158

Otley, D. (1999). Performance management: a framework for management control systems research. Management Accounting Research, 10(4), 363-382. https://doi.org/10.1006/mare.1999.0115

Pallant, J. (2011). SPSS Survival Manual: A step by step guide to data analysis using SPSS (4th ed.). Allen \& Unwin.

Pandey, S. K. (2015). Performance Information Use: Making Progress but a Long Way to Go. Public Performance \& Management Review, 39(1), 1-6. https://doi.org/10.1080/15309576.2016.1071158

Penner, L. a, Dovidio, J. F., Piliavin, J. a, \& Schroeder, D. a. (2005). Prosocial behavior: multilevel perspectives. Annual Review of Psychology, 56, 365-392. https://doi.org/10.1146/annurev.psych.56.091103.070141

Perry, James L, Hondeghem, A., \& Wise, L. R. (2010). Revisiting the Motivational Bases of Public Service Motivation: Twenty Years of Research and an Agenda for the Future. Public Administration Review, 70(5), 681-690. https://doi.org/10.1111/j.15406210.2010.02196.x

Perry, James L, \& Hondeghem, A. (2008). Building Theory and Empirical Evidence about Public Service Motivation. International Public Management Journal, 11(1), 3-12. https://doi.org/10.1080/10967490801887673

Perry, J. L. (1996). Measuring Public Service Motivation: An Assessment of Construct Reliability and Validity. Journal of Public Administration Research and Theory, 6(1), 5-22. https://doi.org/10.1093/oxfordjournals.jpart.a024303

Perry, J.L. \& Wise, L. R. (1990). The Motivational Bases of Public Service. Public Administration Review, 50, 367-373. https://doi.org/10.2307/976618

Piliavin, J. A. \& Charng, H. W. (1990). Altruism: A Review of Recent Theory and Research. Annual Review of Sociology, 16, 27-65. https://doi.org/10.1146/annurev.so.16.080190.000331

Public Services Commission. (2012). Performance Management Policy for the Public Services of Ghana.

Ritz, A. (2009). Public service motivation and organizational performance in Swiss federal government. International Review of Administrative Sciences, 75(1), 53-78. https://doi.org/10.1177/0020852308099506

Ritz, A., Brewer, G. A., \& Neumann, O. (2016). Public Service Motivation: A Systematic Literature Review and Outlook. Public Administration Review, 76(3), 414-426. https://doi.org/10.1111/puar.12505

Sanderson, I. (2001). Performance Management, Evaluation and Learning in 'Modern' Local Government. Public Administration, 79(2), 297-313. https://doi.org/10.1111/14679299.00257

Schott, C., van Kleef, D. D., \& Steen, T. (2015). What Does It Mean and Imply to be Public Service Motivated? American Review of Public Administration, 45(6), 689-707. https://doi.org/10.1177/0275074014533589

Shahmehr, F. S., Safari, N., Jamshidi, M. J., \& Yaghoobi, N.-M. (2014). The Impact of Performance Management on Mission Statement and Operational Goal Setting. International Journal of Business and Management, 9(11), 189-198. 
Abane, J. A., \& Phinaitrup, B.
Performance Management Practices and Motivation in

Developing Countries: A Further Validation of the Public

Service Motivation Construct in Ghana

https://doi.org/10.5539/ijbm.v9n11p189

Steijn, B. (2008). Person-Environment Fit and Public Service Motivation. International Public Management Journal, 11(1), 13-27. https://doi.org/10.1080/10967490801887863

Tabachink, B. G \& Fidell, L. S. (2014). Using Multivariate Statistics. Pearson Education. http://www.pearsoncustomlibrary.com/ISBN/0205849571

Vandenabeele, W. (2007). Towards a Theory of Public Service Motivation: An Institutional Approach. Public Management Review, 9(4), 545-556. https://doi.org/10.1080/14719030701726697

Vandenabeele, W. (2008). Development of a Public Service Motivation Scale: Corroboration and Extending Perry's Measurement Instrument. International Public Management Journal, 11(1), 143-167. https://doi.org/10.1080/10967490801887970

Vandenabeele, W. (2009). The mediating effect of job satisfaction and organizational commitment on self-reported performance: more robust evidence of the PSMperformance relationship. International Review of Administrative Sciences, 75, 11-34. https://doi.org/10.1177/0020852308099504

Vandenabeele, W. (2014). Explaining Public Service Motivation: The Role of Leadership and Basic Needs Satisfaction. Review of Public Personnel Administration, 34(2). https://doi.org/10.1177/0734371X14521458

Waal, A. a. De, \& Counet, H. (2009). Lessons learned from performance management systems implementations. International Journal of Productivity and Performance Management, 58(4), 367-390. https://doi.org/10.1108/17410400910951026

Wright, B. E., \& Christensen, R. K. (2010). Public service motivation: A test of the job attraction-selection-attrition model. International Public Management Journal, 13(2), 155-176. https://doi.org/10.1080/10967491003752012

Wright, B. E., Christensen, R. K., \& Pandey, S. K. (2013). Measuring Public Service Motivation: Exploring the Equivalence of Existing Global Measures. International Public Management Journal, 16(2), 197-223. https://doi.org/10.1080/10967494.2013.817242

Wright, B. E., Moynihan, D. P., \& Pandey, S. K. (2012). Pulling the Levers: Transformational Leadership, Public Service Motivation, and Mission Valence. Public Administration Review, 72(2), 206-215 https://doi.org/10.1111/j.1540-6210.2011.02496.x

Yang, K. \& Hsieh, J. Y. (2007). Managerial Effectiveness of Government Performance Measurement: Testing a Middle-Range Model. Public Administration Review, 861879. https://doi.org/10.1111/j.1540-6210.2007.00774.x 


\section{Appendix A}

\section{Abbreviations}

$\begin{array}{ll}\text { ATTRACT- } & \text { Attraction to policymaking } \\ \text { CID- } & \text { Civic duty } \\ \text { COMM-Commitment to the public interest } \\ \begin{array}{ll}\text { COMP- Compassion } \\ \text { GAR- } & \text { Greater Accra Region } \\ \text { LG- } & \text { Local government } \\ \text { LGs- } & \text { Local governments } \\ \text { MMAs- metropolitan and municipal assemblies } \\ \text { LGS- } & \text { Local Government Service } \\ \text { PM- } & \text { Performance management } \\ \text { PMPs- } & \text { Performance management practices } \\ \text { PME- } & \text { Performance monitoring and evaluation } \\ \text { PERIMP- } & \text { Performance improvement } \\ \text { PEREVIEW- } & \text { Performance review } \\ \text { PSM- } & \text { Public service motivation } \\ \text { SS- } & \text { Self-sacrifice } \\ \text { SP- } & \text { Strategic planning } \\ \text { VIF- } & \text { Variance Inflation Factor }\end{array}\end{array}$

